
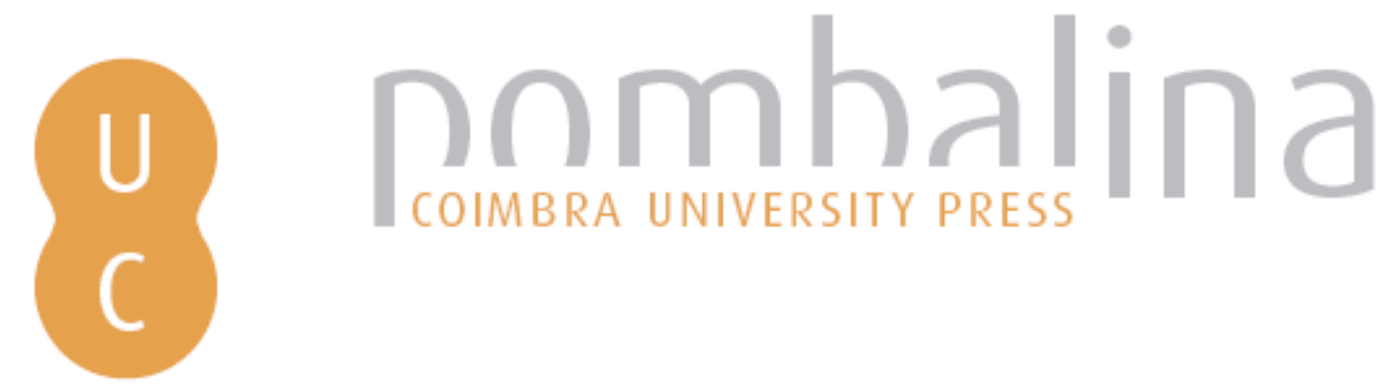

\title{
Uma proposta para detecção automática de problemas de representação no processo de generalização cartográfica de cartas topográficas
}

\author{
Autor(es): $\quad$ Sluter, Claudia Robbi; Castro, Mônica Cristina \\ Publicado por: Imprensa da Universidade de Coimbra \\ URL \\ persistente: URI:http://hdl.handle.net/10316.2/37066 \\ DOI: $\quad$ DOI:http://dx.doi.org/10.14195/978-989-26-0983-6_13 \\ Accessed : $\quad$ 26-Apr-2023 03:57:16
}

A navegação consulta e descarregamento dos títulos inseridos nas Bibliotecas Digitais UC Digitalis, UC Pombalina e UC Impactum, pressupõem a aceitação plena e sem reservas dos Termos e Condições de Uso destas Bibliotecas Digitais, disponíveis em https://digitalis.uc.pt/pt-pt/termos.

Conforme exposto nos referidos Termos e Condições de Uso, o descarregamento de títulos de acesso restrito requer uma licença válida de autorização devendo o utilizador aceder ao(s) documento(s) a partir de um endereço de IP da instituição detentora da supramencionada licença.

Ao utilizador é apenas permitido o descarregamento para uso pessoal, pelo que o emprego do(s) título(s) descarregado(s) para outro fim, designadamente comercial, carece de autorização do respetivo autor ou editor da obra.

Na medida em que todas as obras da UC Digitalis se encontram protegidas pelo Código do Direito de Autor e Direitos Conexos e demais legislação aplicável, toda a cópia, parcial ou total, deste documento, nos casos em que é legalmente admitida, deverá conter ou fazer-se acompanhar por este aviso.

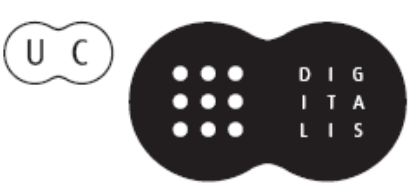




\section{$\forall$ \\ TAS DAS I JORNADAS LUSÓFONAS DE CIÊNCIAS E TECNOLOGIAS DE INFORMAÇÃO GEOGRÁFICA}

Editores

José Gomes dos Santos

Cidália Fonte

Rui Ferreira de Figueiredo

Alberto Cardoso

Gil Gonçalves

José Paulo Almeida

Sara Baptista 


\section{A RTI G O 13}

\section{UMA PROPOSTA PARA DETECÇ̃̃o AUTOMÁtica de PROBLEMAS DE REPRESENTAÇÃO NO PROCESSO DE GENERALIZAÇÃo CARTOGRÁfica de CARTAS TOPOGRÁfiCAS}

SLUTER, Claubia Robbi ${ }^{1}$ \& CASTRO, Mônica Cristina ${ }^{2}$

\footnotetext{
${ }^{1}$ Departamento de Geomática da Universidade Federal do Paraná; Curso de Engenharia Cartográfica Curso de Pós-Graduação em Ciências Geodésicas; Caixa Postal 19001 Centro Politécnico, 81531-990 Curitiba - Paraná; Tel: 55413361 3636, email: robbi@ufpr.br

2 Mestranda do Curso de Pós-Graduação em Ciências Geodésicas; email: castro.monica@gmail.com
}

\section{RESUMO}

Uma carta produzida a partir da redução de escala pode apresentar problemas de representação, como a aglomeração de feições, o que prejudica a sua legibilidade. Para resolver tal problema e manter a comunicação cartográfica eficiente, a generalização cartográfica deve ser aplicada nesta carta derivada. Quando estes problemas são tratados como condições geométricas e analisados com parâmetros gráficos podem ser utilizados como indicativo da necessidade de generalização. Este trabalho tem como objetivo automatizar a deteç̧ão de problemas de representação relacionados às feições de edificações, limites de propriedade e vias de uma carta topográfica urbana na escala 1:5.000 derivada de uma na escala 1:2.000. Isto é feito através de regras de um sistema especialista, desenvolvido no aplicativo ModelBuilder, que, com auxilio de ferramentas de análise espacial, realiza medidas geométricas sobre as feições de interesse. Como resultado, novas camadas de dados são geradas contendo as feições que apresentam os problemas de representação e estas são destacadas das demais. A generalização é um processo subjetivo e dependente do profissional 
que o realiza. Logo, a automatização de parte deste processo pode ajudar a formaliza-lo, tornando-o menos dependente da influencia e do controle humano e, assim, mais eficiente.

\title{
PALAVRAS-CHAVE
}

Generalização cartográfica, Problemas de representação, Visibilidade, Legibilidade, Condições geométricas.

\author{
a proposal for automatic detection of \\ REPRESENTATION PROBLEMS IN CARTOGRAPHIC \\ GENERALIZATION OF TOPOGRAPHIC MAPS
}

\begin{abstract}
When a map is produced by scale reduction, representation problems can appear, for example clustering features. These impair the map legibility. The solution to this problem is the application of cartographic generalization in the new map. When these problems are view as geometric conditions and analyzed with graphical parameters they can be used as an indicative of the need for generalization. This work aims to automate the detection of representation problems of features of buildings, property boundaries and roads in an urban topographic map, scale 1:5.000 derived from a scale 1:2.000. This is done by rules of an expert system, developed in ModelBuilder, which, make geometric measures on features of interest with aid of spatial analysis tools. As results, new data layers are generated containing the features that show the representation problems. Generalization is a subjective and human-dependent process. Therefore, automating part of this process can help formalize it, making it less dependent of human control and influences, and thus more efficient.
\end{abstract}

\section{KEYWORDS}

Cartographic generalization, Representation problems, Visibility, Legibility, Geometric conditions.

\section{INTRODUÇÃO}

A generalização cartográfica é o processo que minimiza ou evita os problemas de visualização que afetam a legibilidade de uma carta topográfica, mantendo eficiente a comunicação cartográfica, quando esta tem sua escala reduzida (D’ALGE, 2007, 1). Isto ocorre através da redução da quantidade de informações, do realce das mais importantes e da fidelidade aos dados originais (BARD \& RUAS, 2004, 328). Várias decisões tomadas 
ao longo do processo de generalização são subjetivas devido à influência humana de quem a realiza, pois profissionais diferentes interpretam os problemas decorrentes da redução de escala da sua própria maneira, usando sua experiência, intuição e conhecimento da área (JOÃO, 1998, 4). No entanto, não é razoável generalizar uma carta sem a intervenção de um profissional, pois não há consenso de como realiza-la, logo a automatização de todas as etapas do processo não é possível. João (1998, 5) afirma que "sistemas computacionais (como SIG) têm potencial para oferecer bons resultados para generalização. Um benefício de um sistema computacional seria a capacidade iterativa - a habilidade de refazer o processo até alcançar um resultado aceitável." Assim, o uso de sistemas computacionais para realizar algumas das etapas da generalização é recomendável.

Um indicativo da necessidade de aplicar a generalização são os problemas de representação encontrados em cartas derivadas. Ao reduzir a escala de uma carta, a quantidade de informações representadas aumenta, porém o espaço reservado para a representação continua o mesmo, o que pode originar problemas como congestionamento e coalescência, também chamados de condições geométricas, as quais podem ser tratadas como problemas de visibilidade e legibilidade (LECORDIX, 2011, 4). A detecção destas é feita de modo visual, através da avaliação cartométrica. No entanto, realizar esta avaliação somente de modo visual demanda tempo e esforço. Então, surge a necessidade de automatizar a detecção destas condições aliada à definição de medidas geométricas.

As cartas topográficas dos municípios paranaenses são construídas a partir de dados de levantamentos topográficos ou técnicas fotogramétricas, na escala 1:2.000. Segundo Nalini $(2005,4)$, as cartas derivadas desta escala base passam apenas pelo processo de seleção das classes de feições que serão representadas e esta etapa é feita com base no conhecimento e experiência dos técnicos que especificam e utilizam estes produtos. Assim, estas cartas não atendem as necessidades destes profissionais, pois como o processo de generalização cartográfica não é aplicado, as cartas derivadas apresentam problemas de representação.

Esta pesquisa tem como objetivo propor a detecção automática dos 
problemas de visualização relacionados às feições de edificações, limites de propriedade e vias de uma carta topográfica urbana na escala 1:5.000, derivada de uma carta na escala 1:2.000, visando manter sua legibilidade.

\section{APRESENTAÇÃo do TEMA}

De acordo com a SCC - Swiss Society of Cartography (2002, 39) "a generalização cartográfica consiste na seleção e combinação de objetos importantes para a compreensão da carta, na manutenção da precisão posicional, na preservação das características das feições e na representação destas de modo claro”. A redução de escala de uma carta gera a necessidade de restringir os dados para que apenas o essencial para cada escala derivada seja representado (op. cit.).

Com o desenvolvimento da cartografia digital e da evolução constante dos sistemas de informações geográficas, a generalização cartográfica passou a ser realizada em meio digital e novos problemas e conceitos foram propostos e definidos para este processo (MCMASTER \& SHEA, 1992, 3). De acordo com os autores, (op. cit.) a generalização digital consiste na derivação de dados, a partir de um banco de dados geográficos, através de transformações espaciais e de atributos. Tal processo visa manter a clareza da representação numa escala menor, sendo este, segundo os autores, o principal objetivo da generalização. A automatização de todas as etapas da generalização só pode ocorrer se as complexidades e as diversidades deste processo puderem ser resolvidas por processos computacionais, o que demanda traduzir passos subjetivos e intuitivos em regras específicas (JOÃO, 1998, 5).

Devido a tais obstáculos, há modelos conceituais que formalizam as etapas da generalização. Entre estes, o mais difundido é o modelo de McMaster \& Shea. Este modelo é composto por três partes: (1) objetivos filosóficos, por que generalizar? (2) avaliação cartométrica, quando generalizar? e (3) transformações espaciais e de atributos, como generalizar?

McMaster \& Shea (1992, 42) alegam que a generalização digital é necessária quando o usuário não consegue compreender o que está representado devido à falta de clareza da representação. Três aspectos devem 
ser considerados para realizar a generalização: condições geométricas, medidas espaciais e holísticas, e controles de transformação. Entre as condições geométricas mencionadas pelos autores estão: congestionamento, coalescência, conflito, complicação, inconsistência e imperceptibilidade. Estas condições geométricas são definidas por MCMASTER \& SHEA (1992, 43 a 44) como:

- Congestionamento: aglomeração de símbolos devido à alta densidade de feições (idem, ibidem).

- Coalescência: quando há aproximação excessiva e/ou sobreposição parcial ou total de feições, ocasionada pelo fato da distância entre as feições estar abaixo da resolução do sistema computacional em que a carta será visualizada, o que pode fazer com que feições se 'toquem' (idem, ibidem).

- Conflito: ocorre quando a representação de uma feição está em conflito lógico com o fundo da carta. Por exemplo, dada duas feições com uma relação lógica entre si: linear e de área, como uma rodovia sobre uma ponte, ligando duas cidades-(idem, ibidem).

- Complicação: o processo de generalização depende de alguns fatores como, complexidade dos dados, temporalidade, seleção das técnicas de iteração e seleção dos parâmetros. Durante a generalização ambiguidades na aplicação dos algoritmos podem surgir devido a tais fatores (idem, ibidem).

- Inconsistência: surge quando a aplicação dos operadores de generalização é feita de um modo não uniforme (idem, ibidem).

- Imperceptibilidade: quando os símbolos também são reduzidos e podem apresentar dimensões menores do que o tamanho mínimo perceptível ao olho humano (idem, ibidem).

A presença de uma (ou mais) das condições geométricas mencionadas acima é um indicativo de que a generalização deve ser feita para minimizar os efeitos da redução de escala.

Regnauld $(2001,312)$ afirma que as pesquisas em generalização automática tem como foco reduzir a complexidade do processo no que se refere aos operadores, que realizam as transformações espaciais e semânticas nos dados. Antes de generalizar as edificações, o autor afirma que é preciso 
satisfazer algumas condições de legibilidade que guiam o processo como distância mínima entre feições, tamanho mínimo e orientação.

\section{METODOLOGIA}

Este trabalho foi desenvolvido com a base cartográfica digital do município paranaense de Campo Largo, disponibilizado pelo PARANACIDADE, com auxilio do software ArcGIS 10 e seu aplicativo ModelBuilder. A base cartográfica apresenta as seguintes características: sistema geodésico SAD 1969, projeção cartográfica UTM zona 22S, escala 1:2.000, datada de 1996. Tais especificações são determinadas pela Câmara Técnica de Cartografia e Geoprocessamento - CTCG do Estado do Paraná, Brasil.

Esta base apresenta diversas informações cartográficas. Optou-se por realizar o estudo dos problemas de representação em função das feições de edificações, limites de propriedade e vias em virtude da necessidade das cartas derivadas atenderem aos seguintes projetos desenvolvidos no PARANACIDADE, que auxiliam no planejamento urbano: Planta Genérica de Valores Imobiliários, Cadastro Técnico Imobiliário Urbano, Infraestrutura Urbana, Pavimentação Pública (NALINI, 2005, 7). Estes documentos cartográficos devem apresentar imóveis das áreas urbanas, quadras, sistema viário e loteamento do município, os quais correspondem às feições citadas.

Esta pesquisa é composta por sete etapas:

I. Redução geométrica da escala da carta de 1:2.000 para 1:5.000;

II. Detecção visual das condições geométricas com relação às classes de feições definidas;

III. Verificação de quais condições geométricas podem caracterizar os problemas de visibilidade e legibilidade;

IV. Definição dos parâmetros gráficos;

V. Identificação das funções de análise espacial que podem ser usadas para detectar as condições geométricas;

VI. Projeto do sistema especialista, e

VII. Implementação da solução por sistema especialista. 


\subsection{Redução geométrica da carta}

Com auxílio do software ArcGIS, a escala da carta topográfica foi reduzida de 1:2.000 para 1:5.000 sem que as feições sofressem alguma alteração na sua representação. Esta operação consiste na simples alteração da escala no campo correspondente na barra de ferramentas do programa. A redução geométrica é necessária para que a avaliação cartométrica seja realizada. A Figura 1 apresenta um recorte da carta na escala original (a) e na escala reduzida (b).

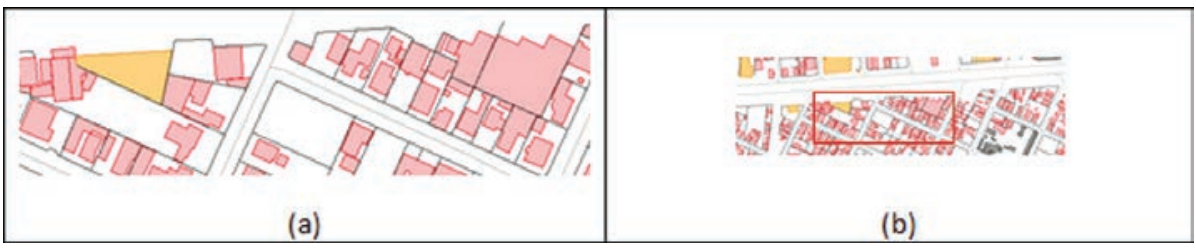

Figura 1 - Recorte da carta topográfica de Campo Largo na escala original 1:2.000 (a) e da carta reduzida (b)

\subsection{Detecção visual das condições geométricas}

A avaliação cartométrica consiste na detecção visual das condições geométricas com relação às classes de feições definidas e auxilia na identificação dos parâmetros gráficos específicos para estas condições. Para isto, analisou-se, em meio digital, a carta reduzida para a identificação prévia de situações que interferem na leitura da carta. Após esta análise, regiões contendo problemas de visibilidade e legibilidade, foram delimitadas e impressas.

A Figura 2 ilustra um recorte de uma área de estudo que apresenta problemas de legibilidade. Devido à proximidade excessiva entre as edificações, a distinção destas é prejudicada. Este problema dificulta a leitura da carta, pois se vê somente uma edificação representada, quando há duas ou mais. Há ainda edificações e detalhes nestas que não são totalmente visíveis devido ao seu tamanho. 


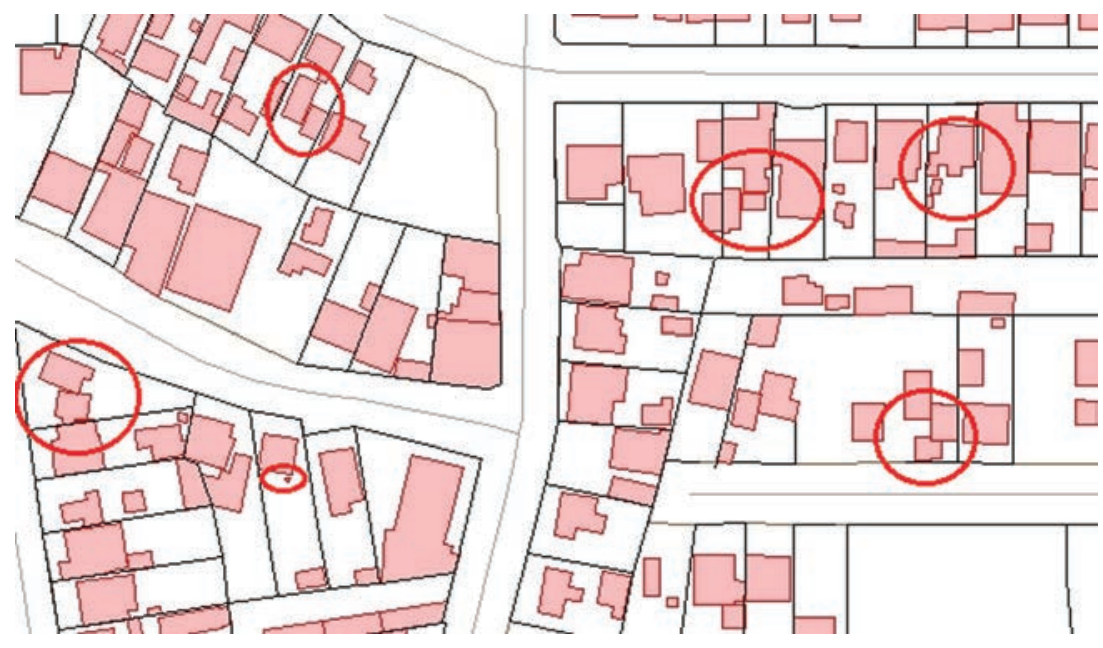

Figura 2 - Recorte da carta na escala 1:5.000 com a identificação de áreas com problemas de representação

\subsection{Condições geométricas, problemas de representação e parâmetros gráficos}

Tendo conhecimento dos problemas de representação presentes na carta reduzida e da definição destes de acordo com McMaster \& Shea, é possível identificar quais parâmetros gráficos devem ser estabelecidos e relacionados a cada condição para que estas possam ser detectadas automaticamente. Tais parâmetros gráficos correspondem às feições representadas e suas características, como comprimento do lado do quadrado, espessura da linha, espaçamento entre feições, entre outros. Congestionamento e coalescência se relacionam com a proximidade excessiva entre feições e sempre que houver coalescência de feições, haverá congestionamento e, por consequência, problemas de legibilidade. A imperceptibilidade ocorre devido ao tamanho dos símbolos estarem abaixo do mínimo perceptível e se relaciona com o problema de visibilidade. A Tabela 1 apresenta as condições geométricas detectadas visualmente e seus respectivos parâmetros gráficos. 
Tabela 1 - Condições geométricas, parâmetros gráficos e problemas de representação

\begin{tabular}{|c|c|c|}
\hline Condições Geométricas & Parâmetros Gráficos & Problemas \\
\hline Imperceptibilidade & $\begin{array}{c}\text { Tamanho mínimo das feições } \\
\text { Tamanho dos detalhes das } \\
\text { áreas dos polígonos } \\
\text { Espessura das linhas }\end{array}$ & Visibilidade \\
\hline $\begin{array}{c}\text { Congestionamento } \\
\text { Coalescência }\end{array}$ & $\begin{array}{c}\text { Espaçamento entre áreas e linhas } \\
\text { Espaçamento entre áreas }\end{array}$ & Legibilidade \\
\hline
\end{tabular}

A definição dos parâmetros gráficos consiste na caracterização destas medidas geométricas baseada em recomendações encontradas em trabalhos de generalização cartográfica para áreas urbanas, como SCC (2002), Issmael (2003), Nalini (2005) e Taura (2007). Como o entendimento destes critérios é possível saber quais operadores são necessários aplicar diante das circunstâncias encontradas. A Tabela 2 abaixo apresenta os valores e os símbolos dos parâmetros gráficos empregados neste trabalho.

Tabela 2 - Símbolos e dimensões mínimas utilizados no sistema especialista

\begin{tabular}{|c|c|c|}
\hline Símbolo & Detalhe & $\begin{array}{c}\text { Tamanho } \\
\text { mínimo }(\mathrm{mm})\end{array}$ \\
\hline & $\begin{array}{c}\text { Espaçamento entre } \\
\text { áreas }\end{array}$ & 0,15 \\
\hline & $\begin{array}{l}\text { Espaçamento entre } \\
\text { áreas e linha }\end{array}$ & 0,20 \\
\hline & Detalhes da forma & 0,25 \\
\hline & $\begin{array}{l}\text { Quadrado sólido } \\
\text { (lado) }\end{array}$ & 0,30 \\
\hline & $\begin{array}{l}\text { Quadrado vazado } \\
\text { (lado) }\end{array}$ & 0,50 \\
\hline $\bar{z}$ & Linha contínua & 0,20 \\
\hline+2 & $\begin{array}{l}\text { Espaçamento entre } \\
\text { linhas }\end{array}$ & 0,20 \\
\hline
\end{tabular}

3.4. Funções de análise espacial usadas para detectar condições geométricas

A identificação das ferramentas do ArcGIS tem como objetivo validar os parâmetros gráficos identificados na etapa anterior e utiliza-los no de- 
senvolvimento do sistema especialista. Apenas as ferramentas disponíveis no software para dados vetoriais foram analisadas. Outras ferramentas de gerenciamento de dados, como criar campo, para a criação de campos na tabela de atributos, e adicionar ligação, para ligar tabelas criadas a uma determinada feição, também foram identificadas e utilizadas no desenvolvimento do sistema especialista.

\subsection{Sistema especialista}

O projeto do sistema especialista foi desenvolvido utilizando o aplicativo ModelBuilder, disponível no ArcGIS, sendo então denominado de modelo, o qual permite que tarefas passem a ser examinadas como regras específicas que unem em sequência as ferramentas de análise espacial já existentes no ArcGIS ou as criadas em função das necessidades dos usuários. O sistema é baseado em regras de decisão definidas a partir do conhecimento das condições geométricas, com a caracterização de cada parâmetro gráfico e sua relação com as classes de feições. Para cada classe, foi criado um modelo. Deste modo, as classes são analisadas separadamente em relação aos problemas identificados. Assim, cada classe tem dois modelos, um para detecção das condições de congestionamento e coalescência, que são caracterizadas por parâmetros de mesmo valor, e outro modelo para a condição de imperceptibilidade, a qual está em desenvolvimento. A Figura 3 ilustra um modelo genérico para as condições de congestionamento e coalescência.

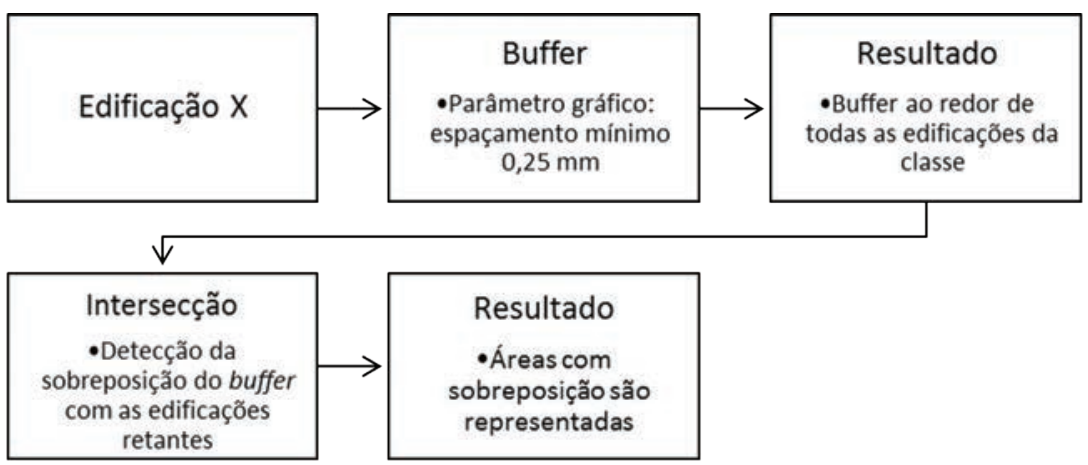

Figura 3 - Esboço do sistema especialista 
Para cada classe de edificação, o primeiro passo é a aplicação de um buffer de 1,25 m, referente aos parâmetros de distância mínima entre feições, tanto de área como de linhas. Em seguida, duas ferramentas podem ser aplicadas: intersecção ou recortar, para identificar quais edificações se sobrepõem às edificações comerciais ou ao layer criado anteriormente com a aplicação do buffer. Esta regra origina um novo arquivo que contem as partes das edificações que se sobrepõem ao buffer. Após isto, o sistema faz uso da ferramenta juntar para que todas as feições identificadas anteriormente fiquem em somente um arquivo. Do contrário, o sistema irá criar arquivos novos para cada classe de edificação, mesmo não havendo sobreposição alguma. A Figura 4 ilustra parte do sistema referente as edificações comerciais.

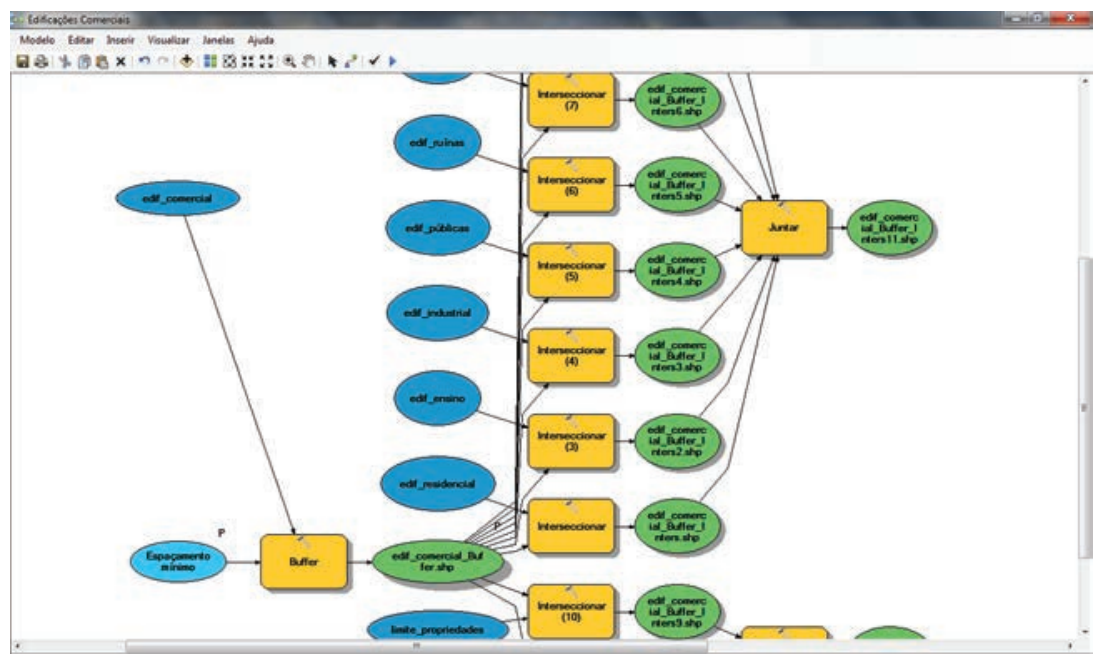

Figura 4 - Recorte do sistema especialista referente às edificações comerciais

\section{APRESENTAÇÃo DOS DAdOS}

O sistema criado identifica as feições que apresentam as condições de congestionamento e coalescência. Ao executar o modelo do sistema especialista, uma nova camada de dados é adicionada automaticamente ao layout atual do ArcGIS. Todas as edificações foram analisadas em relação às outras edificações, e aos limites de propriedade e às vias. As ferramentas utilizadas no desenvolvimento do sistema foram: buffer, 
intersecção, recortar, juntar, proximidade. Esta última adiciona na tabela de atributos um novo campo identificando qual classe de edificação está próxima às feições da classe analisada. É possível utilizar o mesmo parâmetro gráfico empregado no buffer nesta ferramenta, no caso 1,25 m. Como resultado, a tabela de atributos apresenta o FID, o número de identificação de cada objeto próximo, a distância deste para a feição em questão e a qual classe este pertence, como a Figura 5 apresenta.

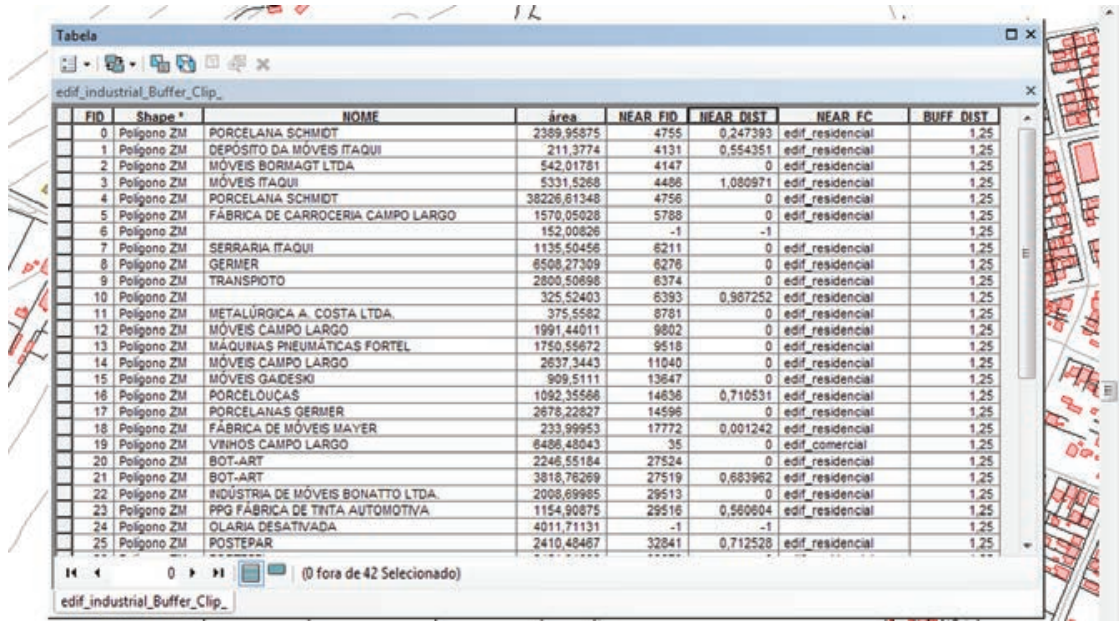

Figura 5 - Tabela de atributos da classe edificações industriais gerada pelo sistema especialista

A Figura 6 apresenta o resultado do modelo criado, já executado, para as edificações de saúde. As feições identificadas pelo círculo 1 se relacionam ao parâmetro gráfico espaçamento entre áreas. Tais feições são apresentadas em preto. O círculo 2 corresponde ao espaçamento entre a edificação de saúde (em amarelo, devido ao arquivo criado pelo buffer) e os limites de propriedade. As feições lineares em vermelho significam que estas estão abaixo da distância mínima.

Como observado, a identificação das áreas que apresentam congestionamento e coalescência pode não ser imediata devido a como as feições resultantes do modelo estão representadas. O usuário pode alterar a cor da camada de dados resultante como pode abrir a tabela de atributos e analisa-la para localizar a feição de interesse, e visualizar qual é a edificação mais próxima a esta e que causa o problema de legibilidade. 


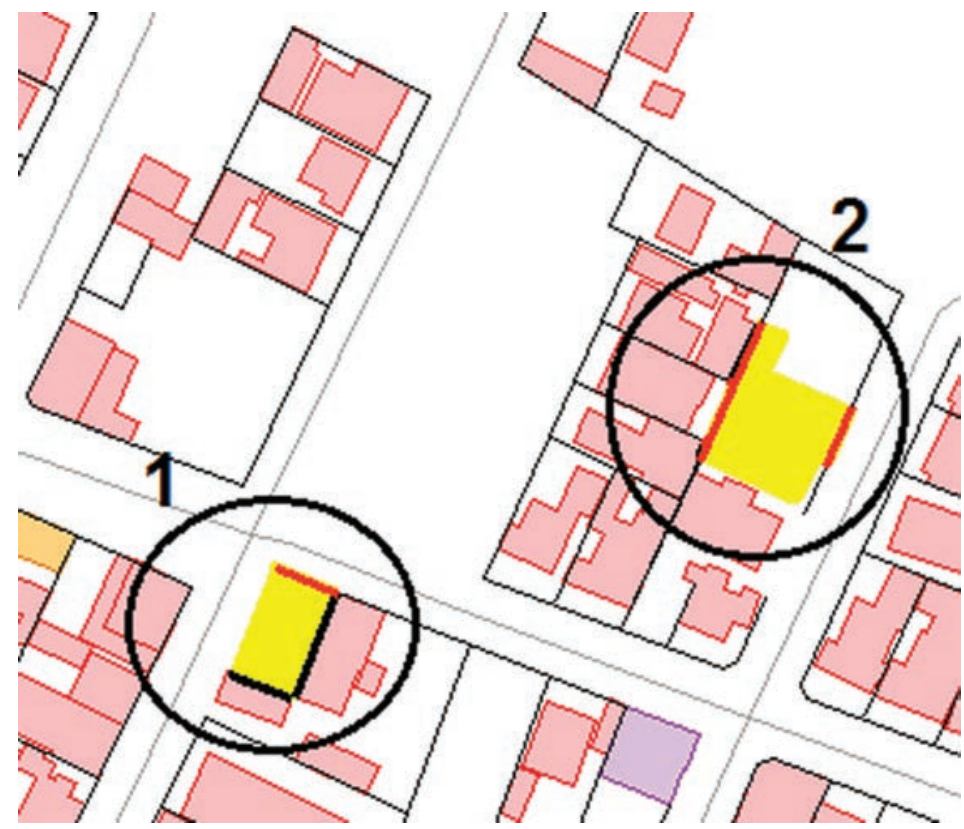

Figura 6 - Resultado do sistema especialista criado para a classe de edificações de saúde

\section{DiscuSS Ão doS RESULTADOS PARCIAIS}

Nos arquivos gerados como resultado do sistema especialista pode-se identificar apenas as partes das edificações que se sobrepõem ao buffer resultante, e não todo o polígono da edificação. Isto dificulta a localização dos problemas de legibilidade na escala 1:5.000, na carta reduzida. Quando a carta é vista na escala original, 1:2.000, o problema é facilmente identificado. O ideal seria localizar as áreas com problemas na escala reduzida. Para tal, é possível adicionar as ferramentas proximidade para apontar qual classe de edificação está localizada abaixo da distância mínima. Após o modelo ser executado, o usuário pode analisar a tabela de atributos da edificação analisada e acrescentar no modelo a ferramenta selecionar e no campo expressão, incluir a expressão que indique qual classe de edificação está presente na tabela de atributos, como a Figura 7 ilustra, 'NEAR_FC'='edif_residencial. No entanto, isso requer a interferência do usuário, o que é contrário ao objetivo do trabalho. 


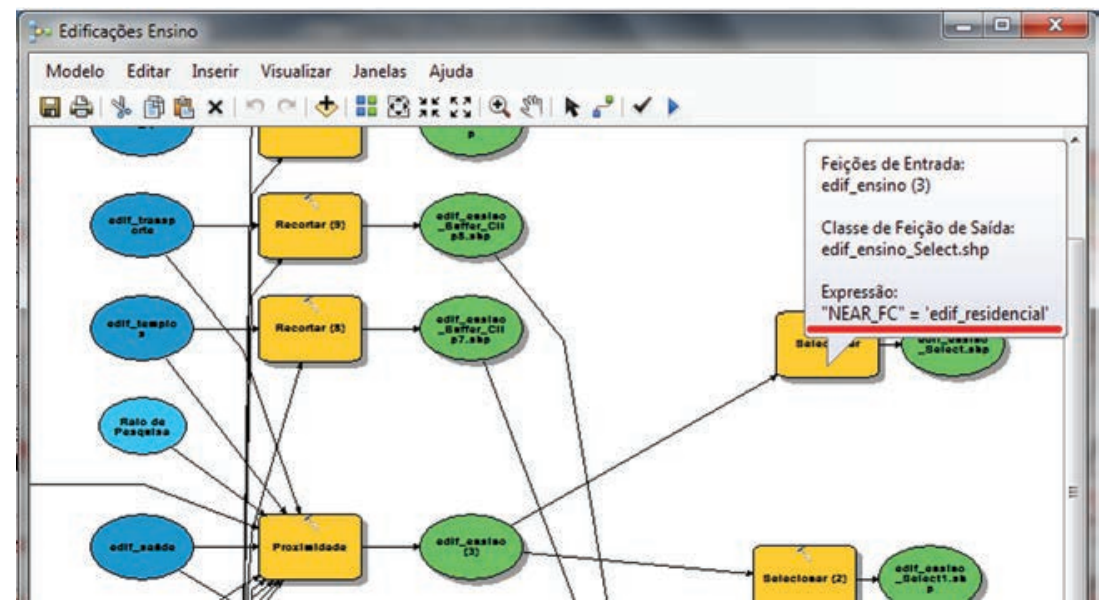

Figura 7 - Modelo do sistema especialista da classe edificações ensino com a inclusão da ferramenta selecionar

Devido à quantidade de edificações residenciais, sugere-se dividir o modelo de modo que as edificações sejam analisadas por bairro ou número de identificação, FID, através de iterações, presentes no próprio ModelBuilder. Esta abordagem proporciona uma otimização na execução computacional destas operações.

Com todos os modelos executados, pode-se afirmar que as áreas de maior concentração residencial apresentam maior índice de problemas de legibilidade, devido à proximidade entre as edificações, os limites de propriedade e as vias. Outras apresentam este problema devido ao fato de serem regiões industriais. Neste caso, a distância entre as edificações de conjuntos industriais causa problemas de legibilidade.

\section{CONCLUSÃo}

O presente trabalho destacou a dificuldade de formalizar o processo de generalização cartográfica. Conforme REGNAULD (2001, 213), a generalização automática já inicia com informações limitadas, pois há situações e relacionamento entre feições que o sistema especialista não 
pode prever. É possível criar regras no modelo que, após o sistema já ter sido executado uma vez, tais situações podem ser identificadas, no entanto, isto requer a interação humano-computador.

Pode-se afirmar que a automatização da detecção dos problemas de legibilidade através de regras de um sistema especialista criado no ModelBuilder é eficaz. Porém, a identificação de cada uma das edificações que devem ser generalizadas ainda requer a interferência do usuário.

Tratar os problemas de representação em função dos parâmetros gráficos associados às condições geométricas pode tornar a generalização menos dependente da interpretação humana e mais eficiente.

\section{BIBLIOGRAFIA}

BARD, Sylvian \& RUAS, Anne (2004) - Why and How evaluating generalised data?, 13th International Symposium on Spatial Data Handling. Springer. pp 327-342.

D'AlGE, Julio Cesar Lima (2007) - Generalização Cartográfica em Sistemas de informação geográfica: Aplicação aos Mapas de Vegetação da Amazônia Brasileira. São Paulo. Tese (Doutorado em Engenharia) - Escola Politécnica da Universidade de São Paulo. 150 p.

ISSMAEL, Linda Soraya (2003) - Generalização Cartográfica: Determinação de Operadores e de Escalas Catastróficas. Dissertação (Mestrado em Ciências em Engenharia Cartográfica) - Instituto Militar de Engenharia. Rio de Janeiro. 250 p.

JOÃO, Elsa Maria (1998) - Causes and consequences of Map Generalisation. Taylor and Francis, $1^{\mathrm{a}}$ ed. London School of Economics, 266p.

LECORDIX, François (2011) - Cartographic Generalisation Processo on French Topographic Mapping. Curitiba. In: VII Colóquio Brasileiro de Ciências Geodésicas. 19p.

MCMASTER, Robert B. \& SHEA, K. Stuart (1992) - Generalization in Digital Cartography. Washington: Association of American Geographers, 133p.

NALINI, Virginia Thereza (2005) - Avaliação Cartométrica da Base Cartográfica Digital Adequada à Gestão Urbana Derivada por Generalização Cartográfica a Partir da Escala de Origem 1:2.000. Dissertação (Mestrado em Ciências Geodésicas) - Universidade Federal do Paraná. Curitiba . 106 p.

REGNAULD, Nicolas. (2001) - Contextual Building Typification in Automated Map Generalization. Algorithmica, Nova York, n 30, p 312-333. Disponivel online 
no endereço url: http://geog.ucsb.edu/ kclarke/G232/Generalization2.pdf (acedido em 12 February, 2013).

SWISS SOCIETY OF CARTOGRAPHY (2002) - Maps Graphics and Generalisation. Cartographic Publication Series no 17. 126p.

TAURA, Tatiana Aiko (2007) - Estudo da Simbologia para Cartas nas Escalas 1:2.000, 1:5.000 e 1:10.000 de Mapeamento Urbano do PARANACIDADE e Generalização Cartográfica. Dissertação (Mestrado em Ciências Geodésicas) - Universidade Federal do Paraná. 93p. 
Série Documentos

Imprensa da Universidade de Coimbra

Coimbra University Press

2015

- U M

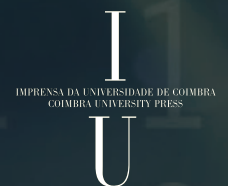

